\title{
Parametric Cost Modelling for Investment Casting
}

Marco Mandolini ${ }^{1(凶)}$, Federico Campi $^{1}$, Claudio Favi ${ }^{2}$, Paolo Cicconi $^{3}$, Michele Germani ${ }^{1}$, and Roberto Raffaeli ${ }^{4}$

${ }^{1}$ Department of Industrial Engineering and Mathematical Sciences, Università Politecnica delle Marche, Via Brecce Bianche 12, 60131 Ancona, Italy

m.mandolini@univpm. it

2 Department of Engineering and Architecture, Università degli Studi di Parma, Parco Area delle Scienze 181/A, 43124 Parma, Italy

3 Dipartimento di Ingegneria, Università degli Studi Roma Tre, Via della Vasca Navale 79, Roma, Italy

4 Department of Sciences and Methods for Engineering, Università degli Studi di Modena e Reggio Emilia, Via Amendola 2, 42122 Reggio Emilia, Italy

\begin{abstract}
This paper presents a parametric cost model for estimating the raw material cost of components realized employing the investment casting process. The model is built using sensitivity analysis and regression methods on data generated by an analytic cost model previously developed and validated by the same authors. This is the first attempt of developing a parametric cost model for investment casting based on activity-based costing. The proposed cost model accounts component volume, material density and material price. The error in estimating the raw material cost for components whose volume is within the common range of investment casting is around $11 \%$.
\end{abstract}

Keywords: Parametric cost modelling - Sensitivity analysis · Investment casting $\cdot$ Cost estimating relationship $\cdot$ Cost estimation

\section{Introduction and Literature Review}

The lost wax casting technique is one of the oldest and most advanced of the metallurgical arts [1]. The precision casting process is capable of producing complex castings with tight tolerances and good surface finish, and can meet the highest performance standards, such as those typical of turbojet engines. Other advantages of this process include the ability to melt materials that are impossible to forge and difficult to process employing other technologies. Wax casted components have weight ranging from few grams to a couple of dozens of $\mathrm{kg}$ and dimensions ranging from $5 \mathrm{~mm}$ to $300 \mathrm{~mm}$. The tolerance ranges normally achievable in investment cast casting is $\pm 1 \%$ of the nominal size, with a minimum of $\pm 0,10 \mathrm{~mm}$ for dimensions lower than $10 \mathrm{~mm}$ [2], with a minimum roughness of $3.2 \mu \mathrm{m}[3]$.

The manufacturing cost is one of the most important design requirements, for many kinds of products, which drives most of the technical and technological solutions [4]. 
For casting processes, different analytic cost models have been developed based on the process's peculiarities. Several researchers [5-7] have identified the major cost items of a casting process, such as material, tooling, labour, energy and overheads. The DFM Concurrent Costing ® software developed by Boothroyd Dewhurst Inc. [8] has an analytic and detailed investment casting cost estimation module aimed at product designers. It considers most phases of the process (pattern and core manufacturing, pattern and cluster assembly, cleaning and etching, investment operation, melting, sintering, break out, blast cleaning and cut off).

However, analytical cost estimation methods and related cost models can be used only during the embodiment and detailed design phases, when the product is almost completely defined. For estimating manufacturing cost at the conceptual design phase, parametric cost models seem more suitable for this aim. The parametric cost estimation method involves formulating relations between product characteristics and its cost using available data. The issues of using analytic cost models for estimating the investment casting process during the design phase is even stronger for investment casting. This manufacturing process consists of several manufacturing phases and product/process cost drivers, which are too many for being managed by a design engineer.

Nowadays, industry 4.0, internet of things and data analytic are paradigms that foster the popularity of parametric cost modelling and cost estimating relationship methods [9]. Nonetheless, in literature, only few works presenting parametric cost models for investment casting. Among them, the most significant is that one presented by Creese [10], which considers the following product drivers: number of surface patches, number of patterns, volume of the part, floor area, material density and price. The parametric cost model is built according to historical data and this activity is also called activitybased costing $[11,12]$. However, it is not recognizable any scientific paper presenting a parametric cost model for investment casting process, based on data got from an analytic model. This is the novelty of the paper.

Based on a well-established cost estimating relationship approach [9], this paper presents a parametric cost model for investment casting. The model is built using sensitivity analysis and data regression methods on data generated by an analytic cost model previously developed and validated by the same authors.

\section{Cost Estimation Relationship Building Process}

The estimation of the manufacturing cost for wax-casted products generally requires complex cost estimation relationship, which need various inputs by the designer. Often, the designer knows this data only at an advanced stage of part design. The purpose of this section and in general of the study is to obtain a parametric relationship which allows a cost estimation of the part using data already knows in the early stages of component design. The cost estimating relationship (CER) is the distinguishing feature of parametric cost estimation. A CER is a mathematical expression that describes how the values of, or changes in, a "dependent" variable are partially determined, or "driven," by the values of, or changes in, one or more "independent" variables [9]. The CER building process described later is divided in three parts and it uses the method developed by the International Society of Parametric Analysts [9]. 


\subsection{Data Collection}

All parametric estimating techniques, including CERs and complex models, need credible data before they can be used effectively. Parametric techniques require the collection of historical cost data and the associated non-cost information and factors that describe and strongly influence those costs (technical non-cost data). Technical non-cost data describes the physical, performance, and engineering characteristics of a system, subsystem or individual item. Cost data are obtained using an analytical cost model for investment casting, developed in a previous work, which is an improvement of that one proposed by Boothroyd and Dewhurst [8] and taken as reference. The approach for this improvement consists of four steps, hereunder summarized.

The first step consisted in collecting equations and data, available in Boothroyd and Dewhurst [8], within an electronic spreadsheet in which investment casting process cost has been divided in 13 phases: (i) core manufacturing, (ii) pattern manufacturing, (iii) pattern assembly, (iv) cluster assembly, (v) dissolving core, (vi) cleaning and etching, (vii) investing pattern cluster, (viii) melt out, (ix) sintering, (x) melting, (xi) break out, (xii) blast cleaning and (xiii) cut off. The costs of each phase are composed by process costs (manufacturing, setup and consumables costs) and raw material costs (the costs related to the casted metal).

The second step consisted in organizing two workshops with foundries to improve the cost model.

During the third step all the improvements to the investment casting cost model proposed in DFM have been integrated in the electronic spreadsheet developed at step 1. In this manner, it was possible to draft the cost breakdown for investment casting and detect the most cost expensive phases: (ii) pattern manufacturing ( $12 \div 20 \%$ ), (iv) cluster assembly $(11 \div 12 \%)$, (vii) investing pattern cluster $(14 \div 15 \%)$, (ix) sintering $(\sim 11 \%)$ and $(\mathrm{x})$ melting $(32 \div 39 \%)$, which globally represents the $87 \div 90 \%$ of the product cost.

In the fourth step the cost model has been evaluated by comparing the costs obtained with the proposed model and the actual values of around twenty components provided by the foundries. For all the components it can be noted a deviation lower than $10 \%$.

Starting from the cost breakdown and taking into consideration the most cost expensive phases, cost drivers are the following: batch size; part volume; part thickness; raw material price; raw material density; labour cost. For each cost driver a reference value was fixed. These reference values refer to a component of a food packaging machine (weight: $2 \mathrm{~kg}$, dimensions: $160 \times 172 \times 15 \mathrm{~mm}$ ) realized in stainless steel AISI316 and manufactured in Italy.

For having enough data for the parametric relationship development, each cost driver indicated above was varied between a maximum and a minimum value and raw material and process costs derived from the analytical model were collected. This sensitivity analysis was carried out in two phases: in the first phase (a) only one cost driver at a time was changed, keeping the others at reference value; instead in the second phase (b) two cost drivers together were changed. The maximum, minimum and reference values of each cost driver are indicated in Table 1. 
Table 1. Reference, maximum and minimum values of cost drivers

\begin{tabular}{l|l|l|l}
\hline Cost driver [U.O.M.] & Reference value & Max value & Min value \\
\hline Batch size $[\mathrm{ad}]$ & 1000 & 2000 & 10 \\
\hline Part volume $\left[\mathrm{m}^{3}\right]$ & 0.00026300 & 0.00063120 & 0.00001325 \\
\hline Part thickness $[\mathrm{mm}]$ & 25 & 50 & 2 \\
\hline Raw material price $[€ / \mathrm{kg}]$ & 3.4 & 5.4 & 0.8 \\
\hline Raw material density $\left[\mathrm{kg} / \mathrm{m}^{3}\right]$ & 7850 & 15000 & 2000 \\
\hline Labour cost $[€ /$ hour] & 30 & 70 & 3 \\
\hline
\end{tabular}

\subsection{CER Development}

The cost estimating relationship development follows the two-phases analysis indicated above. With the data obtained in the first phase (a) it is possible to evaluate the relationships among the process/raw material costs and the cost drivers. From this first phase it can be concluded that volume and density are the only cost drivers that significantly influence both the cost of the process and the cost of the raw material. The batch size, part thickness, and labour cost affect only the process cost, while a change in the material price only affects the raw material cost. This first step lets to understand the cost drivers to use in the second step to obtain parametric cost relationships. In this study, the focus is about the cost of raw material, which relationship with raw material price, part volume, and density is shown in Fig. 1. For this figure it is possible to observe that raw material cost linearly depends on its unitary price (the higher the unitary price the higher the cost). Raw material cost is related to part volume and density via a step function because, while increasing the weight, pouring and handling systems may change discontinuously.

To build a parametric relationship function of these three cost drivers, it was firstly calculated 26 linear least square regressions (one for each discrete levels of raw material price) between raw material cost, the dependent variable, and part volume, the independent variables. For each regression it was obtained 2 coefficients: the slope and the intercept. Two other linear least square regressions were subsequently made between the obtained coefficients, in this case the dependent variable, and the discrete raw material price levels, the independent variable. By combining the data of the two regressions, a parametric parabolic equation was obtained (1). To develop the previous equation, material density was fixed to the reference value $\left(\rho=7850 \mathrm{~kg} / \mathrm{m}^{3}\right)$, allowing the raw material cost calculation only for part which have the same material density of reference value.

raw material cost $(\rho=7850)=23760.18 \cdot($ part volume $) \cdot($ raw material price $)$

$-2056.62 \cdot($ part volume $)+0.96 \cdot($ raw material price $)-0.12$

Therefore, in order to account the effects of using different materials (e.g. melting temperature, gate volume, etc.) on the raw material cost, a density factor coefficient $\left(f_{\rho}\right)$ it was introduced. Its value varies in function of material density and is equal to 1 for the reference material (AISI 316), less than 1 for materials with a density lower 
than the reference $(0.31$ for Aluminium 1100 ; 0.98 for $\mathrm{G} 1800$ Gy cast iron; 0.99 for 42CrMo4), greater than 1 for material whit a density higher than the reference (1,01 for $39 \mathrm{NiCrMo} 4)$. Then the cost of raw material can be calculated by Eq. (2).

$$
\text { raw material cost }=\mathrm{f}_{\rho} \cdot \text { raw material cost }(\rho=7850)
$$

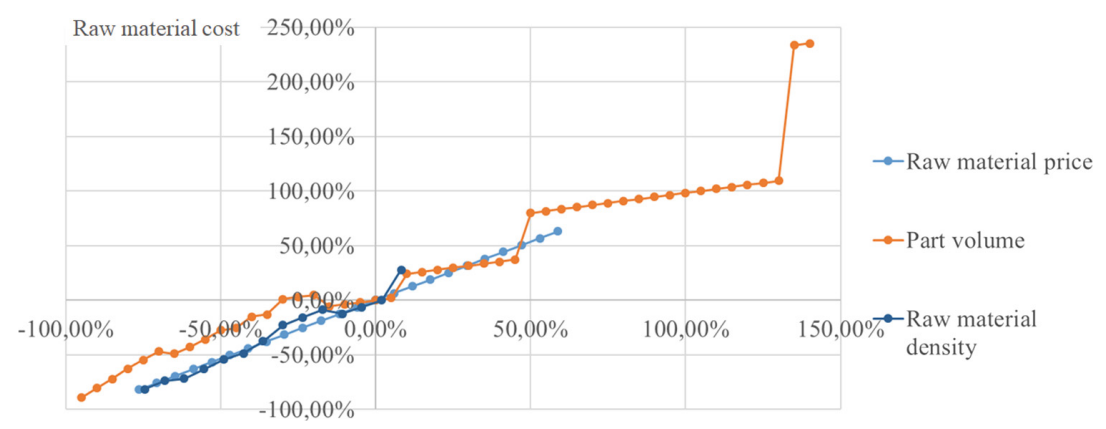

Fig. 1. Sensitivity analysis of raw material density, price and part volume on raw material cost.

\subsection{Validation}

The cost estimating relationship must produce, to a given level of confidence, results within an acceptable range of accuracy. The validation of the previous relationship was carried out comparing its results with those deriving from analytical cost model of investment casting. Table 2 presents the absolute cost deviation between estimated values and the data obtained using the analytical model.

Table 2. Comparison between analytical model (reference) and parametric model (calculated)

\begin{tabular}{l|l|l|l|l}
\hline Component & Material & Reference cost & Calculated cost & Absolute deviation \\
\hline 1 & Aluminium 1100 & $€ 3.77$ & $€ 4.40$ & $17 \%$ \\
\hline 2 & $\begin{array}{l}\text { G 1800 grey cast } \\
\text { iron }\end{array}$ & $€ 2.53$ & $€ 2.44$ & $4 \%$ \\
\hline 3 & $42 \mathrm{CrMo} 4$ & $€ 5.85$ & $€ 6.48$ & $11 \%$ \\
\hline 4 & $39 \mathrm{NiCrMo} 4$ & $€ 8.29$ & $€ 9.44$ & $14 \%$ \\
\hline 5 & AISI 316 & $€ 20.03$ & $€ 23.77$ & $19 \%$ \\
\hline Average absolute deviation & & & $11 \%$ \\
\hline
\end{tabular}

Results show a low deviation between the raw material cost estimated using the parametric model and the data obtained using the analytical model (the average absolute deviation is approx. 11\%). This result demonstrates the goodness of the proposed parametric model. 


\section{Conclusions}

This paper presented a parametric cost model for investment casting, developed according to the method presented in the parametric estimating handbook. The elementary data used for developing the cost model was obtained from an analytic cost model developed in a previous work and validated with the cooperation of two foundries. By employing sensitivity analysis and regressions methods, the paper presented a parametric cost model for estimating the raw material cost of wax casted parts. The error in estimating the raw material cost for components whose volume is within the common range of investment casting is around $11 \%$.

Future research, following the method used in this work, should aim to develop parametric cost models for the estimating variable (i.e.: consumable, process and setup) and fixed costs (i.e. tooling cost).

\section{References}

1. Pattnaik, S., Karunakar, B.D., Jha, P.K.: Developments in investment casting process-a review. J. Mater. Process. Technol. 212(11), 2332-2348 (2012)

2. ASM Handbook, Volume 15: Casting, ASM International (2008)

3. Ashby, M.: Materials Selection in Mechanical Design, 3rd edn. (2004)

4. Sohlenius, G.: Concurrent engineering. CIRP Ann. Manuf. Technol. 41(2), 645-655 (1992)

5. Chronister, T.G.: The Cost of making castings. Casting Eng. 7(4), 8-11 (1975)

6. Jain, P.L.: Analysis of cost effectiveness for selection of pattern material. Indian Foundry J. 33(1), 27-30 (1987)

7. Kulkarni, A.: Cost control in foundries through innovation. Indian Foundry J. 34(1), 21-25 (1988)

8. Boothroyd, G., Dewhurst, P., Knight, W.A.: Product Design for Manufacture and Assembly, 3rd edn. CRC Press (2011)

9. Parametric Estimating Handbook, 4th edn. International Society of Parametric Analysts (2008)

10. Creese, R., Adithan, M.: Estimating and Costing for the Metal Manufacturing Industries, 1st edn. CRC Press (2019)

11. Langmaak, S., Wiseall, S., Bru, C., Adkins, R., Scanlan, J., Sóbester, A.: An activity-basedparametric hybrid cost model to estimate the unit cost of a novel gas turbine component. Int. J. Prod. Econ. 142(1), 74-88 (2013)

12. Ardiansyah, R., Sutopo, W., Nizam, M.: A parametric cost estimation model to develop prototype of electric vehicle based on activity-based costing. In: 2013 IEEE International Conference on Industrial Engineering and Engineering Management, pp. 385-389 (2013) 
Open Access This chapter is licensed under the terms of the Creative Commons Attribution 4.0 International License (http://creativecommons.org/licenses/by/4.0/), which permits use, sharing, adaptation, distribution and reproduction in any medium or format, as long as you give appropriate credit to the original author(s) and the source, provide a link to the Creative Commons license and indicate if changes were made.

The images or other third party material in this chapter are included in the chapter's Creative Commons license, unless indicated otherwise in a credit line to the material. If material is not included in the chapter's Creative Commons license and your intended use is not permitted by statutory regulation or exceeds the permitted use, you will need to obtain permission directly from the copyright holder. 